\title{
EFEITO DA IRRIGAÇÃO E DA ONTOGENIA SOBRE A ESTIMATIVA DA ÁREA FOLIAR DE Hancornia speciosa Gómez (MANGABEIRA) ${ }^{1}$
}

\author{
FRANCISCO DE ALMEIDA LOBO², CARMEN EUGENIA RODRÍGUEZ ORTÍZ ${ }^{3}$, \\ ISABELA CODOLO DE LUCENA ${ }^{4}$, MARCOS ARDUIN 5
}

RESUMO - A estimativa da área foliar por meio de curvas de regressão que empregam o produto do comprimento pela largura do limbo como variável independente, é uma prática comumente empregada na análise de crescimento vegetal. Entretanto, dependendo da natureza do material vegetal e das condições de cultivo, é possível a ocorrência de variações que afetam essa relação alométrica, o que implica a não universalidade de uma única curva de regressão. Devido a esse problema, o presente trabalho teve como objetivo realizar uma avaliação do efeito da irrigação e da ontogenia sobre a estimativa da área foliar da Hancornia speciosa, para testar a hipótese de que a irrigação afetaria tal relação alométrica. Verificou-se que os modelos de regressão obtidos para as plantas irrigadas e para as não irrigadas diferiram entre si, sendo que houve a necessidade da inclusão da área foliar específica no modelo de estimativa da área foliar das plantas não irrigadas. A não inclusão dessa variável no modelo de regressão acarretou uma diferença de estimativa que se incrementou com a redução da área foliar específica. Em folhas recém-expandidas de plantas irrigadas e não irrigadas, verificou-se diferença na área foliar específica devida à alteração na massa seca e não associada à largura dos tecidos foliares.

Termos para indexação: Hancornia speciosa, relações alométricas, área foliar específica, regressão múltipla, anatomia foliar.

\section{EFFECT OF IRRIGATION AND ONTOGENY IN ESTIMATING THE LEAF AREA OF Hancornia speciosa Gómez (MANGABEIRA)}

\begin{abstract}
Leaf area estimation by regression curves using the product of the length by the breadth of the leaf blade as an independent variable is commonly used in plant growth analysis. However, depending on the nature of the plant species and the farming conditions, it is possible to find variations which affect this allometric relationship, leading to non-universality of a single regression curve. Due to this problem, the present work aimed to evaluate the effect of irrigation and ontogeny in estimating the leaf area of Hancornia speciosa to test the hypothesis that the irrigation would affect such allometric relationship. It was found that the regression models obtained for the irrigated and the non-irrigated plants differed from each other, and there was the need to include specific leaf area into the model to estimate the leaf area for non-irrigated plants. The non inclusion of that variable in the regression model caused a difference on the estimative that increased with the reduction of the specific leaf area. Recently expanded leaves from irrigated and non-irrigated plants differed to each other in their specific leaf area due to dry matter differences but not due to tissue length.

Index terms: Hancornia speciosa, allometric relationships, specific leaf area, multiple regressions, leaf anatomy.
\end{abstract}

\footnotetext{
${ }^{1}$ (Trabalho 175-09). Recebido em: 28-07-2009. Aceito para publicação em: 06-04-2010.

${ }^{2}$ Prof. Dr. da Universidade Federal de Mato Grosso, Faculdade de Agronomia e Medicina Veterinária. Av. Fernando Corrêa da Costa, s/n, Campus Universitário. CEP: 78060-900, Cuiabá-MT, e-mail: f_a_lobo@ufmt.br;

${ }^{3}$ Prof. Dr. da Universidade Federal de Mato Grosso, Instituto de Biociências. Av. Fernando Corrêa da Costa, s/n, Campus Universitário. CEP: 78060-900, Cuiabá-MT, e-mail: cerortiz@ufmt.br;

${ }^{4}$ Doutoranda do Programa de Pós-graduação em Ecologia e Recursos Naturais da Universidade Federal de São Carlos, e-mail: isabelaclucena@gmail.com;

${ }^{5}$ Prof. Dr. da Universidade Federal de São Carlos, Departamento de Botânica, Rodovia Washington Luís, km 235 - SP-310. CEP: 13565-905, São Carlos - SP, e-mail: darduin@power.ufscar.br
} 


\section{INTRODUÇÃO}

As folhas são os órgãos responsáveis pelo intercâmbio gasoso nas plantas. Por essa razão, os estudos relacionados com a assimilação do carbono e os seus efeitos no crescimento e na ontogenia foliar dependem da quantificação da área foliar como subsídio fundamental para a análise dos dados. Como a área foliar específica $(A F E)$ é uma medida que, na análise de crescimento, é comumente empregada como um indicador da variação temporal da espessura do limbo foliar (HUNT, 1990), essa variável está intimamente associada com a ontogenia foliar.

Os métodos para a obtenção da área foliar podem requerer ou não de colheita destrutiva do material vegetal. Se, por um lado, as medições destrutivas se tornam inadequadas quando a área foliar precisa ser mantida nas unidades experimentais ou quando o número de amostras é limitado, por outro, há situações em que o emprego de equipamentos mais sofisticados para as medições não destrutivas não é possível.

Uma forma simples de se determinar a área foliar é a utilização de uma equação de regressão para estimar o seu valor com base em medições lineares das dimensões das folhas (KVĚT; MARSHALL, 1971) evitando a destruição do material. Vários trabalhos têm empregado essa técnica em várias espécies de plantas com folhas de diferentes formatos e tamanhos. Por exemplo, em espécies da família Poaceae, cujas folhas são lanceoladas (KEMP, 1960), em Asteraceae, com limbo deltoide (BANGE et al., 2000), e em Araceae de folhas sagitadas (LU et al., 2004).

Para Hancornia speciosa Gómez (mangabeira), os estudos restringem-se à área foliar, estimada para mudas, sob diferentes condições de viveiro (FONSECA; CONDÉ, 1994). Esses autores propõem o emprego de uma regressão linear simples utilizando dimensões foliares do comprimento e da largura do limbo, ou do produto dessas duas dimensões. Entretanto, não verificaram efeito significativo das condições ambientais sobre as relações alométricas.

As plantas cultivadas em viveiros, sob condições controladas ou semicontroladas, tendem a apresentar características morfofisiológicas nem sempre representativas daquelas cultivadas em campo. Esse aspecto suscita, no mínimo, uma curiosidade acerca de quão possível se pode extrapolar os resultados obtidos em mangabeiras cultivadas em viveiro para aquelas de campo. Ao se tratar da estimativa da área foliar por uma relação alométrica, cujas variáveis são as medidas lineares do limbo foliar, outras variáveis associadas à geometria foliar deveriam ser investigadas. Nesse sentido, o primeiro fator a ser investigado é o processo de desenvolvimento foliar, uma vez que a morfologia varia com a ontogenia (HUNT, 1990). Outros fatores, como a irrigação, a drenagem e a fertilização, também devem ser considerados na avaliação.

O presente trabalho teve como propósito testar a hipótese de que a relação alométrica que emprega o produto do comprimento pela maior largura do limbo foliar da mangabeira é afetada pela irrigação e pela ontogenia foliar.

\section{MATERIAL E MÉTODOS}

O experimento foi conduzido na Fazenda Experimental da Universidade Federal de Mato Grosso, situada no município de Santo Antônio de Leverger, a $30 \mathrm{~km}$ de Cuiabá, com coordenadas geográficas de latitude de $15^{\circ} 47^{\prime} \mathrm{S}$, longitude de $56^{\circ} 04^{\prime}$ W e $140 \mathrm{~m}$ acima do nível do mar.

A área experimental constou de um cultivo de mangabeiras de seis anos de idade divididas em quatro parcelas, plantadas a um espaçamento de $3 \mathrm{~m}$ entre linhas e $3 \mathrm{~m}$ entre plantas. Em duas parcelas, foi instalado um sistema de irrigação por microaspersão para manter as plantas irrigadas durante a estação seca do ano (abril a setembro), com uma quantidade diária de irrigação da ordem de $3 \mathrm{~L}$ por planta que, nas condições locais, é suficiente para restituir a água perdida por evapotranspiração.

Para a realização deste trabalho, foram escolhidas, aleatoriamente, duas parcelas, sendo uma irrigada e a outra não irrigada. A parcela irrigada continha 10 plantas, e a parcela não irrigada, 17.

Durante o período de 23 de fevereiro de 2005 a 30 de junho de 2006, foram realizadas amostragens mensais de três ou quatro folhas em quatro plantas, aleatoriamente, selecionadas e na parcela irrigada na parcela não irrigada. No total, foram analisadas 231 folhas de plantas irrigadas e 237 de não irrigadas.

Após a coleta, as folhas foram acondicionadas em sacos plásticos, contendo em seu interior um tufo de algodão umedecido em água, para manter o ar saturado, e transportadas dentro de um caixa de isopor resfriada por meio do uso de uma bolsa térmica de polietilenoglicol.

As folhas foram avaliadas quanto ao comprimento e à largura, com o emprego de um paquímetro $(50 \mu \mathrm{m}$ de resolução) e fotografadas sobre papel branco com um eixo cartesiano com escala milimetrada, para possibilitar a determinação de suas áreas, com o auxílio do programa SigmaScan Pro V.5.0. Em seguida, as folhas foram individual- 
mente armazenadas em sacolas de papel e levadas à estufa ventilada a $75^{\circ} \mathrm{C}$. Após $48 \mathrm{~h}$, a massa seca foi determinada em balança analítica.

Com os dados de área foliar e massa seca, determinou-se, para cada folha amostrada, o valor de sua área foliar específica $(A F E)$, que é a razão entre $\mathrm{a}$ área foliar e a massa seca foliar.

A estimativa da área foliar foi feita partindose de um modelo de regressão múltipla do segundo grau (Equação 1), com o auxílio do programa SAS V. 6.12. Essa estimativa foi feita tendo como variável dependente a área foliar calculada pelas imagens das fotografias digitais e como variáveis independentes o produto com comprimento pela largura e a $A F E$ :

$y=a+b \cdot x_{1}+c \cdot x_{2}+d \cdot x_{1}^{2}+e \cdot x_{2}^{2}+f \cdot x_{1} \cdot x_{2}(1)$

Em que, $y=$ área foliar; $a=$ coeficiente linear; $b=$ coeficiente de $x_{1} ; x_{1}=$ produto do comprimento pela maior largura do limbo foliar; $c=$ coeficiente de $x_{2} ; \mathrm{x}_{2}=$ área foliar específica; $d=$ coeficiente de $x_{1}^{2} ; e=$ coeficiente de $x_{2}^{2} ; f=$ coeficiente do produto entre $x_{1}$ e $x_{2}$.

O modelo de regressão definitivo foi estabelecido por um processo iterativo, excluindo-se os coeficientes não significativos e procedendo-se a uma nova análise, até que todos os coeficientes do modelo fossem significativos.

A anatomia dos tecidos foliares foi realizada para verificar qual variável poderia ter afetado a $A F E$. Para a determinação da espessura dos tecidos foliares, foram amostradas 2 folhas expandidas de três plantas irrigadas e de três não irrigadas. As coletas ocorreram nos meses de dezembro de 2005 e de fevereiro de 2006 (estação chuvosa), e em abril e junho de 2006 (estação seca). As folhas foram fixadas em FAA 1:1:8 v/v (formaldeído, ácido acético, etanol a 70\%) por um período de 72 horas e transferidas para álcool etílico a 70\% (KRAUS et al., 1998). Para o preparo das lâminas, amostras coletadas entre a borda e a nervura, na região mediana da folha, foram desidratadas em série etanólica, seguido de pré-infiltração em resina e álcool a $96 \% 1: 1$ por 48 horas e incluídos em resina e historresin $(95 \%+5 \%)$ por 48 horas. Para cada folha, foram obtidas secções transversais com espessura de $7 \mu \mathrm{m}$, em micrótomo rotativo (820 Spencer), coradas com azul de toluidina (C. I. 52040) a 0,25\% em bórax a 1\% (PEARSE, 1960), diluído em água destilada $(1: 1, v / v)$. As ilustrações foram obtidas pelo programa Image Pro Plus em microscópio com aumento de 40 X. A análise de variância e prova de médias dos dados originais de espessura dos tecidos foliares foi feita com o emprego do programa SAS V. 6.12.

\section{RESULTADOS E DISCUSSÃO}

Verificaram-se diferenças entre os modelos de regressão obtidos para plantas irrigadas e para não irrigadas. Para mangabeiras irrigadas, o modelo de regressão obtido foi linear simples de primeiro grau, com a variável independente sendo o produto do comprimento pela maior largura do limbo (Figura 1A) e para as plantas não irrigadas, houve efeito significativo da $A F E$, resultando em um modelo de regressão linear múltiplo de primeiro grau, com variáveis independentes sendo o produto do comprimento pela maior largura do limbo foliar e também a $A F E$ (Figura 1B).

Tradicionalmente, o produto do comprimento pela maior largura do limbo foliar é a única variável utilizada para a construção de um modelo de regressão que estabelece a relação alométrica entre essa variável e a área foliar. Considerando o fato de que, para as plantas não irrigadas, o modelo obtido neste trabalho apresenta, além do produto do comprimento pela maior largura do limbo foliar, uma nova variável, a $A F E$, isto despertou a curiosidade acerca da análise da magnitude das diferenças entre um e outro modelo. Verificou-se que essa diferença de estimativa aumenta com a redução dos valores da $A F E$, ou seja, à medida que as folhas se tornam mais velhas, a diferença de estimativa obtida pelos dois modelos de regressão se intensifica (Figura 2).

Para se ter uma ideia do quanto essas diferenças das estimativas da área foliar entre os dois modelos representam em valores numéricos, tomese como exemplo real (dados do experimento) uma folha com $A F E$ igual a $5,95 \mathrm{~m}^{2} \mathrm{~kg}^{-1}$, com valores do comprimento e da largura do limbo foliar iguais a $84 \mathrm{~mm}$ e $33 \mathrm{~mm}$, respectivamente, e outra com $12,05 \mathrm{~m}^{2} \mathrm{~kg}^{-1}$, com valores do comprimento e da largura do limbo foliar iguais a $74 \mathrm{~mm}$ e $32 \mathrm{~mm}$, respectivamente. Para o primeiro caso, utilizando o modelo de regressão linear simples, estima-se uma área foliar igual a $2.172 \mathrm{~mm}^{2}$; ao passo que, utilizando o modelo de regressão linear múltipla, o valor é igual a $2.058 \mathrm{~mm}^{2}$ (uma diferença superior em $114 \mathrm{~mm}^{2}$ alcançada com o modelo simples). Para o segundo caso, utilizando o modelo de regressão linear simples, estima-se uma área foliar igual a $1.845 \mathrm{~mm}^{2}$; enquanto, utilizando o modelo de regressão linear múltipla, o valor é igual a $1.967 \mathrm{~mm}^{2}$ (uma diferença inferior em $122 \mathrm{~mm}^{2}$ alcançada com o modelo simples). Essas diferenças são muito maiores do que aquela que se obtém considerando o limite de resolução instrumental do paquímetro empregado (igual a $50 \mu \mathrm{m}$, portanto uma área de $2.500 \mu \mathrm{m}^{2}$ ou 
$0,0025 \mathrm{~mm}^{2}$ ), ou seja, o erro que eventualmente se poderia cometer devido a uma leitura incorreta do paquímetro, é ainda muitas vezes inferior ao que se obtém pelo uso de modelos de regressão diferentes para estimar a área foliar. Esse erro de estimativa contribui para o incremento do erro aleatório e pode ser suficiente para impedir medições de efeitos de tratamentos nas variações da área foliar, caso não se empregue o modelo de maior exatidão, que é o da regressão múltipla.

De acordo com Fonseca e Condé (1994), a equação de regressão " $y=0,76 x$ " (em que, " $y$ " é a estimativa da área foliar e " $x$ " é o produto do comprimento pela maior largura do limbo foliar da mangabeira) é aquela de melhor ajuste $\left(\mathrm{R}^{2}=\right.$ $0,989)$ e que, por isso, proporciona a obtenção de estimativas da área foliar mais rápidas e precisas (em centímetros quadrados). Quando se confrontam os dados obtidos por aqueles autores, com os obtidos neste trabalho, verifica-se que não há uma concordância perfeita. Comparando-se o modelo proposto por Fonseca e Condé (1994) com os deste trabalho, nota-se que o coeficiente linear daqueles autores é igual a zero, e o angular, igual a 0,76 , ao passo que, neste trabalho, nas plantas irrigadas, o coeficiente linear foi igual a $-131,96839 \pm 131,66894 \mathrm{~mm}^{2}$ (ou $-1,31968 \pm 1,31669 \mathrm{~cm}^{2}$ ), e o coeficiente angular, igual a $0,831541 \pm 0,051604$. Portanto, os modelos lineares propostos por Fonseca e Condé (1994) e apresentados neste trabalho diferem entre si.

Considerando-se que o produto do comprimento pela maior largura do limbo foliar é uma medida que circunscreve a área foliar, espera-se que haja um coeficiente linear significativo e inferior a zero para o modelo de regressão linear simples. Essa observação também foi feita por Fonseca e Condé (1994) com um modelo inicial igual a " $y=-0,038+$ $0,762 \mathrm{x}$ ". Porém, devido ao fato de que o coeficiente linear se apresentou não significativo, os autores refizeram o modelo para que passasse pela origem, o que gerou um segundo modelo mais simplificado.

Uma das razões que explica a diferença encontrada entre o presente trabalho e o relatado por Fonseca e Condé (1994) é que o seu resultado tem aplicação prática para as condições de viveiro no qual o experimento foi conduzido. Portanto, as características foliares das plantas de mangabeira cultivadas em campo, sob efeito ou não de irrigação e com idade fisiológica distinta, determinam relações alométricas particulares e que não são coincidentes com as daquelas mudas cultivadas em viveiro.

Os resultados deste trabalho confirmam a hipótese de que as equações empíricas empregadas na estimativa da área foliar com base em relações alométricas não são universais. Assim, esses modelos não devem ser generalizados, uma vez que, para cada condição de cultivo, é possível que alguns fatores, como irrigação e a $A F E$, possam afetar as relações alométricas e manifestar-se com diferentes graus de significância. Por essa razão, aqueles fatores que forem significativos, devem ser considerados na composição do modelo de regressão a fim de que se obtenha maior exatidão da estimativa.

Em folhas totalmente expandidas, a $A F E$ da mangabeira varia temporalmente e de maneira distinta entre plantas irrigadas e não irrigadas, sendo que folhas recém-expandidas das plantas irrigadas apresentam maiores valores de $A F E$ que as não irrigadas; no entanto, essas diferenças são minimizadas com o envelhecimento das folhas (LOBO et al., 2008).

A irrigação não afetou significativamente as espessuras dos diferentes tecidos foliares (Figura 3). Verificou-se que não houve efeito significativo da irrigação, da época de amostragem e da interação entre esses fatores sobre a epiderme superior, a epiderme inferior, a $1^{\mathrm{a}}$ e a $2^{\mathrm{a}}$ camadas do parênquima paliçádico, o parênquima esponjoso e a espessura total do limbo foliar. Ao se avaliarem estes parâmetros, por meio da análise do grau de associação entre $A F E$ e a espessura dos tecidos foliares, observou-se que a correlação linear foi significativa para as plantas não irrigadas cuja $A F E$ se correlacionou com a espessura do parênquima esponjoso $(r=-0,7003 ; P=0,0357)$, que, por sua própria constituição, não é o maior contribuinte da matéria seca da folha.

Na mangabeira, as diferenças mais marcantes da $A F E$ entre plantas irrigadas e não irrigadas são observadas em folhas recém-expandidas (LOBO et al., 2008). Entretanto, a análise dos cortes anatômicos revelou não haver diferença significativa na espessura dos tecidos foliares dessas plantas (Figuras 3 e 4). Assim sendo, deve-se assumir que essas diferenças de $A F E$ se devem à alocação diferencial de matéria nos tecidos foliares. Esse fato revela um aspecto até então não tratado com relação à $A F E$ e que é o da não universalidade do emprego dessa variável como indicativa da espessura do limbo foliar. 


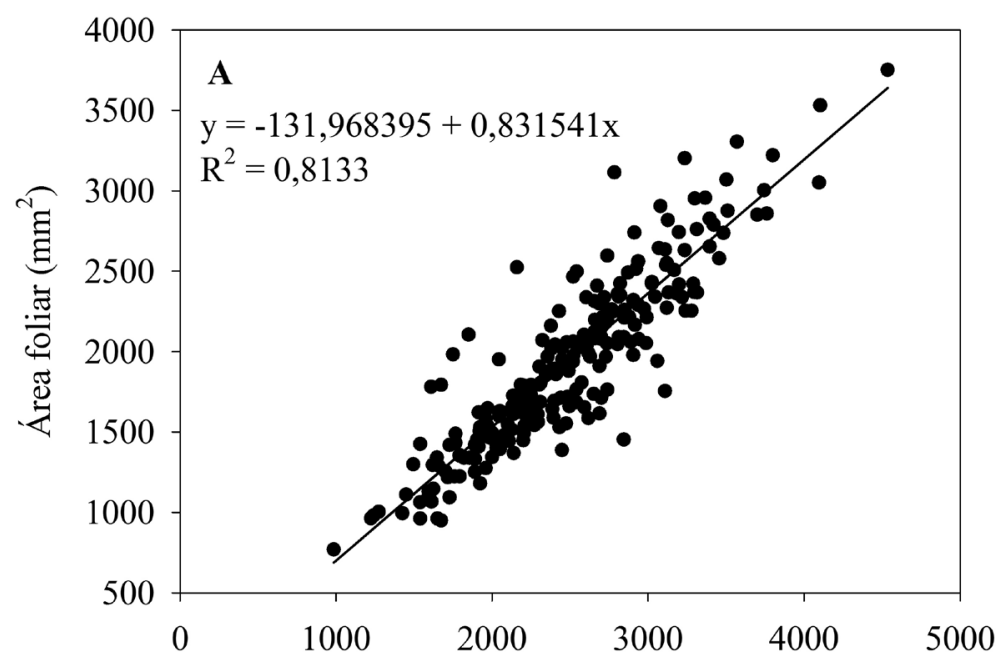

Produto do comprimento pela largura do limbo foliar $\left(\mathrm{mm}^{2}\right)$

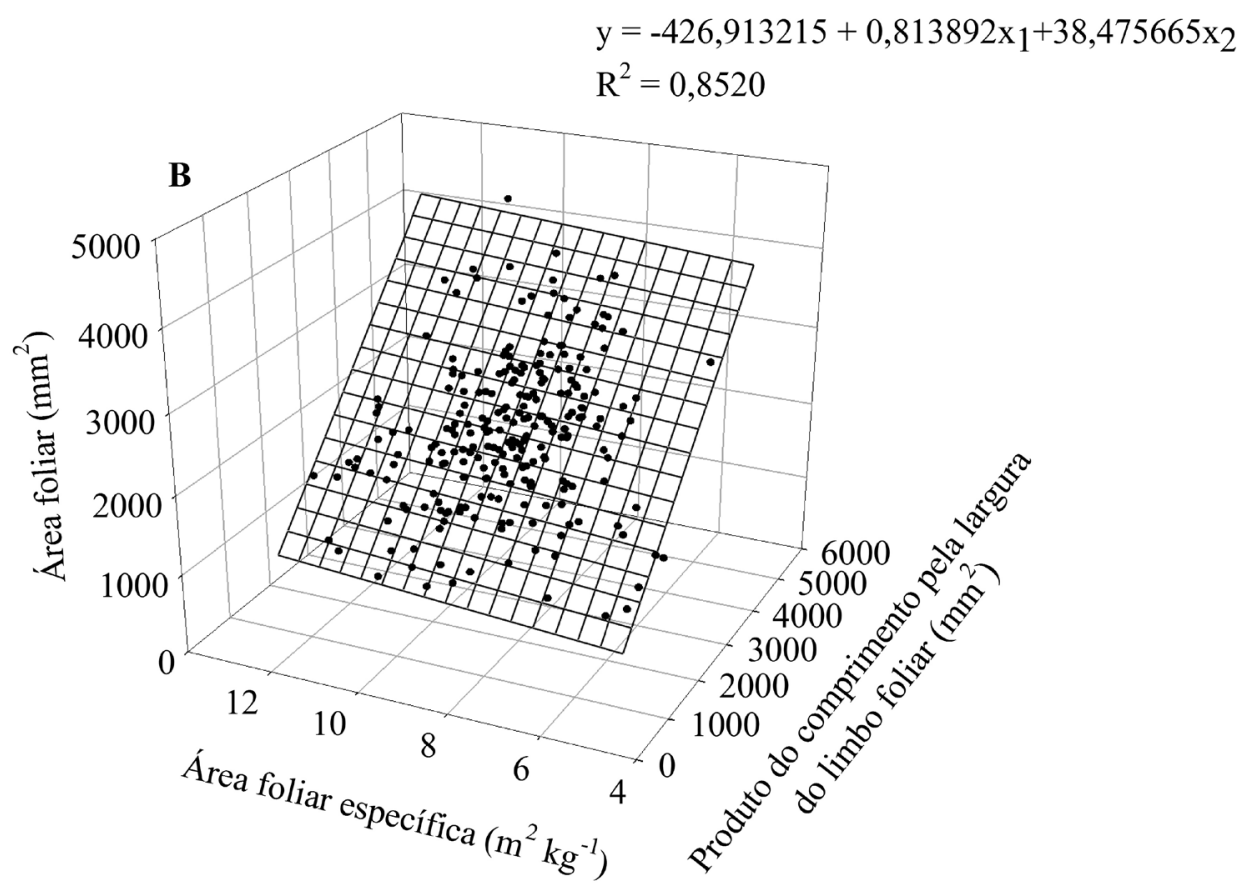

FIGURA 1 - Dispersão dos dados originais e respectivas curvas de regressão para estimativa do índice de área foliar em plantas irrigadas (A) e não irrigada (B), de mangabeira. 


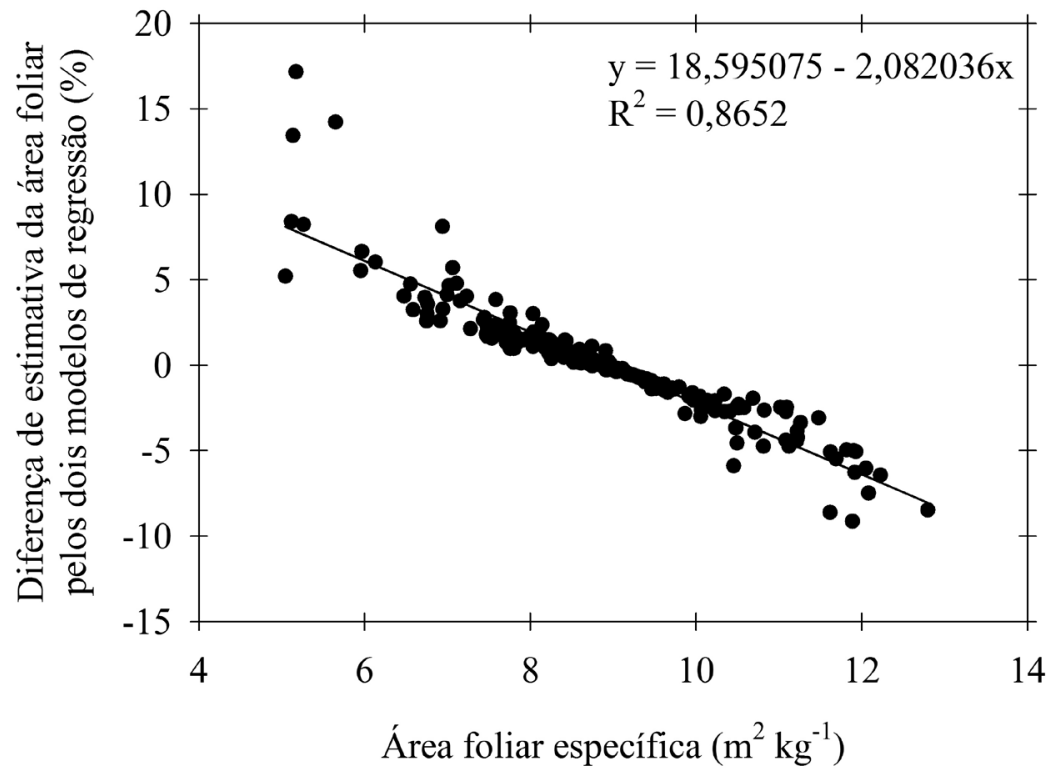

FIGURA 2 - Efeito da área foliar específica na diferença de estimativa da área foliar de mangabeiras não irrigadas obtidas por dois modelos de regressão, um considerando apenas o produto do comprimento pela largura como variável independente e outro incluindo, além desse produto, o valor da área foliar específica. 

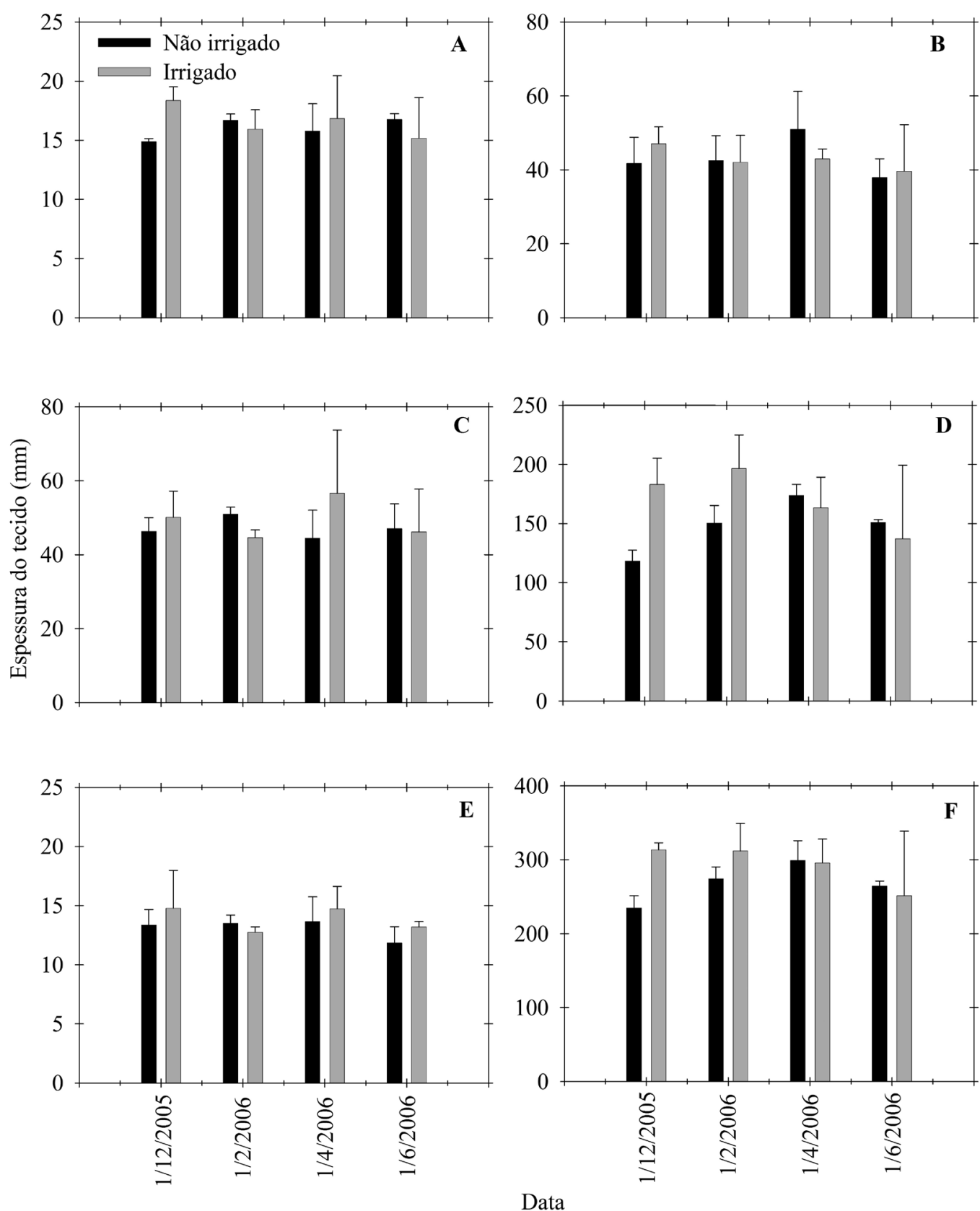

FIGURA 3 - Variação sazonal da espessura da epiderme superior (A), da primeira camada de parênquima paliçádico (B), da segunda camada de parênquima paliçádico (C), do parênquima esponjoso (D), da epiderme inferior (E) e total dos tecidos foliares (F) de plantas irrigadas e não irrigadas de mangabeira. 


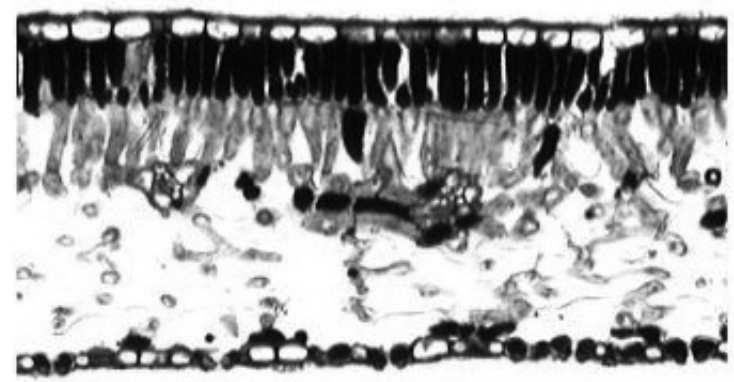

$100 \mu \mathrm{m}$

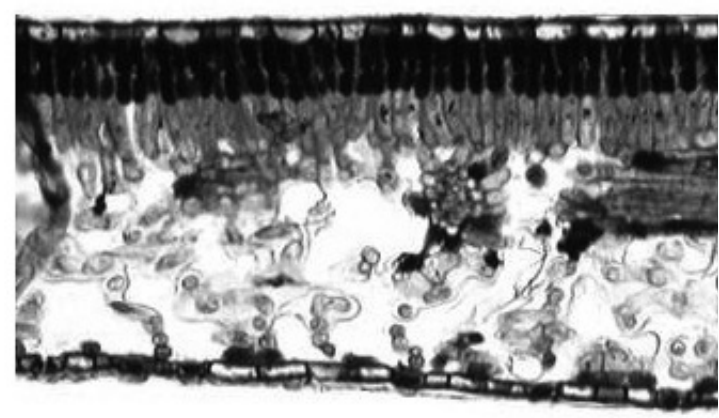

B

FIGURA 4 - Detalhe anatômico de folhas expandidas de plantas de mangabeira irrigadas (A) e não irrigadas (B).

\section{CONCLUSÕES}

1-O regime hídrico sob o qual as plantas de mangabeira são cultivadas, pode afetar a estimativa da área foliar quando esta for realizada por meio de uma regressão linear.

2-Em plantas não irrigadas, o efeito da ontogenia foliar é significativo sobre essa relação alométrica, de maneira que $A F E$ é uma variável que deve ser empregada juntamente com o produto do comprimento pela maior largura do limbo foliar na obtenção de um modelo de regressão múltipla para estimar a área foliar.

3-Desprezando-se o efeito significativo da área foliar específica, em plantas não irrigadas, é possível cometer erros de superestimação da área foliar nas folhas jovens, que têm maiores valores de área foliar específica e de subestimação nas folhas mais velhas, que apresentam menores valores da área foliar específica.

4-Nessa espécie a área foliar específica de folhas recém-expandidas não pode ser utilizada como indicador de alterações na espessura dos tecidos foliares.

\section{AGRADECIMENTOS}

Os autores deste trabalho são gratos à Coordenação de Aperfeiçoamento de Pessoal de Nível Superior, pela concessão da bolsa de iniciação científica à Isabela Codolo de Lucena.

\section{REFERÊNCIAS}

BANGE, M. P.; HAMMER, G. L.; MILROY, S. P.; RICKERT, K. G. Improving estimates of individual leaf area of sunflower. Agronomy Journal, Madison, v.92, p.761-765, 2000.

FONSECA, C. E. L. da; CONDÉ, R. de C. C. Estimativa da área foliar em mudas de mangabeira (Hancornia speciosa Gom). Pesquisa Agropecuária Brasileira, Brasília, v.29, p.593-599, 1994.

HUNT, R. Basic growth analysis. London: Unwin Hyman, 1990. 112 p.

KRAUS, J. E.; SOUSA, H. C.; REZENDE, M. H.; CASTRO, N. M.; VECHI, C.; LUQUE, R. Astra blue and basic fuchsin double staining of plant materials. Biotechnic \& Histochemistry, Baltimore, v.73, p. 235-243, 1998.

KEMP, C. D. Methods of estimating the leaf area of grasses from linear measurements. Annals of Botany, Oxford, v.24, p.491-499, 1960.

KVĚT, J.; MARSHALL, J.K. Assessment of leaf area and other assimilating plant surfaces. In: ŠESTÁK, Z; ČATSKÝ, J.; JARVIS, P. G. (Ed.). Plant photosynthetic production: manual of methods. The Hague: Junk, 1971. p.517-555.

LOBO, F. A.; CAMPELO JUNIOR, J. H.; RODRÍGUEZ-ORTÍZ, C. E.; LUCENA, I.C.; VOURLITIS, G. L. Leaf and fruiting phenology and gas exchange of Mangabeira in response to irrigation. Brazilian Journal of Plant Physiology, Pelotas, v.20, p.1-10, 2008. 
LU, H. Y.; LU, C. T.; WEI, M. L.; CHAN, L. F. Comparison of different models for nondestructive leaf area estimation in taro. Agronomy Journal, Madison, v.96, p.448-453, 2004.
PEARSE, A.G.E. Histochemistry, theoretical and applied. 2. ed. London: J \& A Churchill, 1960. 998 p. 